\title{
Kinetic Monte Carlo modelling the leaching of Raney Ni-Al alloys
}

\author{
N. C. Barnard \& S. G. R. Brown \\ Materials Research Centre, School of Engineering, \\ Swansea University, Singleton Park, Swansea, UK
}

\begin{abstract}
Raney nickel-aluminium alloys are widely used in powder form as catalysts for hydrogenation reactions. While the catalytic powder may be produced via several processing routes in this paper we are concerned with powders manufactured via spray atomization of liquid metal. Before use, the powdered nickel-aluminium alloy undergoes a leaching process carried out in sodium hydroxide solution which dissolves aluminium from the solid and leaves a nanoscopically porous nickel rich product. This product is sometimes referred to as 'spongy nickel'. The kinetics of the process is governed by both the rate of dissolution of aluminium into solution and the rate of surface diffusion of the nickel (which promotes the formation of the nanoscopically porous material). However, individual powder particles may contain more than one NiAl phase. Of particular interest to this work are the $\mathrm{NiAl}_{3}$ and $\mathrm{Ni}_{2} \mathrm{Al}_{3}$ phases. This paper describes a preliminary attempt to model the leaching behaviour of these two phases using a kinetic Monte Carlo simulation.

Keywords: Raney-Ni, leaching, spray-atomization, kinetic Monte Carlo.
\end{abstract}

\section{Introduction}

Raney-type nickel catalysts have been used extensively in hydrogenation reactions, owing to their high catalytic activity in organic reactions. Raney-type Nickel catalysts are obtained from $\mathrm{Ni}-\mathrm{Al}$ alloys, whereby a large proportion of the aluminium present is removed via caustic action: immersion in concentrated $\mathrm{NaOH}$ solution. The starting composition of the Ni-Al alloy and the leaching time/condition has been shown to have an impact on the structure and catalytic performance of the Raney-Ni product [1-5]. Traditionally, the composition used 
for the precursor alloy is $\mathrm{Ni}-50 \mathrm{wt} \% \mathrm{Al}$, consisting of $\mathrm{NiAl}_{3}, \mathrm{Ni}_{2} \mathrm{Al}_{3}$ and $\mathrm{Al}-$ $\mathrm{NiAl}_{3}$ phases. The precursor alloy is often doped with other elements and in an effort to increase the catalytic activity/selectivity of the activated Raney-Ni catalyst, although the effect of these promoters in the leaching process is not considered here.

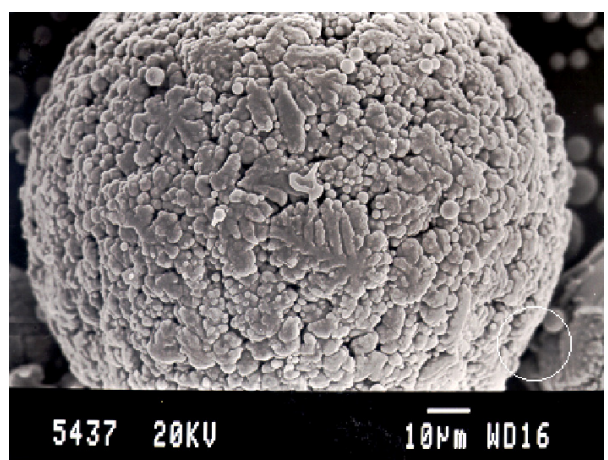

Figure 1: $\quad$ Magnified image of an atomised $\mathrm{Ni}-50 \mathrm{wt} . \% \mathrm{Al}$ powder.

Particles of the Ni-Al alloy may be produced via cast-and-crush or spray atomisation routes. The particles produced range from a few, to in excess of 200 microns diameter. Concentrated aqueous $\mathrm{NaOH}$ is used to 'leach' away a large proportion of the aluminium whilst leaving the nickel. In addition to significantly increasing the surface area of the powder particles, leaching produces hydrogen, which activates the $\mathrm{Ni}$ catalyst:

$$
2(\mathrm{Ni}-\mathrm{Al})_{(\mathrm{s})}+2 \mathrm{OH}_{(\mathrm{aq})}^{-}+6 \mathrm{H}_{2} \mathrm{O}_{(\mathrm{l})} \rightarrow 2 \mathrm{Ni}_{\text {Raney }}+2 \mathrm{Al}(\mathrm{OH})_{4(\mathrm{aq})}^{-}+3 \mathrm{H}_{2(\mathrm{~g})}
$$

During the leaching process $10-20 \mathrm{wt} . \% \mathrm{NaOH}$ is used in order to prevent the formation of bayerite $\left(\mathrm{Al}_{2} \mathrm{O}_{3} \cdot 3 \mathrm{H}_{2} \mathrm{O}\right)$ which is produced when the aluminate formed in solution is precipitated at lower $\mathrm{pH}$.

$$
2 \mathrm{AlO}_{2}^{-}+4 \mathrm{H}_{2} \mathrm{O} \rightarrow \mathrm{Al}_{2} \mathrm{O}_{3} \cdot 3 \mathrm{H}_{2} \mathrm{O}+2 \mathrm{OH}^{-}
$$

The leaching process is carried out at elevated temperatures $\left(\sim 50^{\circ} \mathrm{C}\right)$ and produces a highly pyrophoric catalyst that requires storage in water or alcohol.

Two dominant processes that occur during this process are the dissolution/diffusion of the aluminium and the solid-state diffusion of the nickel present in the phases. Although it has been stated that the $\mathrm{Ni}-50 \mathrm{wt} . \% \mathrm{Al}$ alloy contains the $\mathrm{Al}-\mathrm{NiAl}_{3}$ phase, it is the $\mathrm{NiAl}_{3}$ and $\mathrm{Ni}_{2} \mathrm{Al}_{3}$ phases that are the concern of this paper as observation shows they are by far the most dominant phases present. In order to model the differences in the leaching behaviour of these phases, containing nickel and aluminium in differing ratios, the kinetic Monte Carlo (kMC) technique has been employed. In a seminal paper Erlebacher 
et al [6] used this technique to model the leaching of silver from a $\mathrm{Au}-50 \mathrm{at} . \%$ Ag alloy, examining the evolution of nanoporosity.

An attempt is made here to model the structural transformations during the leaching of the precursor alloy to produce Raney-Ni catalysts using a kMC bondbreaking approach.

\section{Kinetic Monte Carlo (kMC)}

\subsection{Rates of diffusion and dissolution}

In order to simulate the time evolution of the leaching of a Raney-Ni structure a kinetic Monte Carlo method is used. As such, it is a requirement that the processes taking place, i.e. adatom diffusion $(\mathrm{Ni}$ or $\mathrm{Al}$ ) and aluminium dissolution, occur at known rates that serve as the inputs of the model. In the case of the diffusion and dissolution of atoms, the processes are assumed to proceed at a rate described by the following Arrhenius relationships respectively:

$$
\begin{aligned}
& k_{n}^{\text {diff }}=v_{\text {diff }} \exp \left(-\frac{n E_{b}}{k_{b} T}\right) \\
& k_{n}^{\text {diss }}=v_{\text {diss }} \exp \left(-\frac{n E_{b}}{k_{b} T}\right)
\end{aligned}
$$

where $k_{n}^{\text {diff }}$ is the rate constant for diffusion of an atom ( $\mathrm{Ni}$ or Al), $k_{n}^{\text {diss }}$ is the rate constant for dissolution of an atom ( $\mathrm{Al}$ only), the prefactors $v_{\text {diff }}$ and $v_{\text {diss }}$ are attempt frequencies, $n$ is the number of bonds, $k_{b}$ is the Boltzmann constant, $T$ is the absolute temperature $(\mathrm{K})$ and the bond energy is taken as $E_{b}=0.15 \mathrm{eV}$.

The diffusion of both elements present means that the final nanoscopic spongy Nickel structure is not revealed by leaching but rather is constructed during leaching by diffusion of $\mathrm{Ni}$ adatoms. (Although $\mathrm{Ni}$ adatoms do not dissolve there exists a case in the model whereby the Ni atoms may be removed. Should a Ni adatom be present at the surface where it is only neighboured by a single aluminium atom, which is itself selected randomly for dissolution, the $\mathrm{Ni}$ atom would become unattached. For simplicity, this $\mathrm{Ni}$ atom is removed from the simulation.) Equations $3 a$ and $3 b$ mean that atoms with fewer bonds are more likely to dissolve or diffuse. Clearly, adatoms diffusing to lower energy sites (i.e. sites where they have more bonds) will tend to become less likely to diffuse further. In this way Ni adatoms tend to cluster together at exposed surfaces and build up a nanoscopic structure.

Knowledge of the rates of all permitted transitions allows the time increment for each iteration of the model to be calculated. A residence-time algorithm is used by the model to model both of the above processes to model the evolution of the active catalyst. 


\subsection{Bortz-Kalos-Liebowitz (BKL) algorithm}

The Bortz-Kalos-Liebowitz algorithm was used to determine the evolution of the spongy nickel on an event-by-event basis. It proceeds as follows.

1. The time is set to zero; $t=0$.

2. Determine all possible transition states and calculate the cumulative function, $R_{i}=\sum_{j=1}^{i} k_{j}$ for $i=1 \ldots N$, total number of transitions.

3. Get a uniform random number, $u \in(0,1]$.

4. Find the event to carry out, $i$, for which $R_{i-1}<u R<R_{j}$.

5. Find all transitions and associated rates, $k_{i}$ that have changed due to the transition.

6. Get another random number, $u \in(0,1]$.

7. Update the time with $t=t+\Delta t$, where $\Delta t=-\log u / R$.

8. Return to step 2 .

\subsection{Crystal structures}

The simulations are performed with the atoms arranged on a simple cubic orthogonal computational mesh. Since more than one phase maybe present, it cannot be assumed that all sites are suitable for an atom to be positioned in each phase, nor are neighbouring sites on the mesh necessarily suitable for diffusion within a particular phases. The phases considered with respect to crystal structure are $\mathrm{NiAl}_{3}, \mathrm{Ni}_{2} \mathrm{Al}_{3}$ and $\mathrm{NiAl}$. (Within the computational mesh, some vacancies are distributed randomly that permit solid-state diffusion as an event that can take place, although this is of negligible effect.)

\subsection{1 $\mathrm{NiAl}_{3}$}

$\mathrm{The}_{\mathrm{NiAl}}$ phase in an orthorhombic phase, although to permit the use of a cubic mesh the lengths of the lattice are distorted. This allows the approximation of the $\mathrm{NiAl}_{3}$ phase to that of a cubic $\mathrm{AuCu}_{3}$ structure.

\subsection{2 $\mathrm{Ni}_{2} \mathrm{Al}_{3}$}

The $\mathrm{Ni}_{2} \mathrm{Al}_{3}$ phase is less straightforward than that of $\mathrm{NiAl}_{3}$. The structure of this phase can be derived from the $\mathrm{CsCl}$ structure by the removal of every third (111) plane of $\mathrm{Ni}$ atoms [7]. The simple cubic lattice is maintained by a slight contraction along the (111) direction.

\subsubsection{NiAl}

It important to include an NiAl phase in the model since this phase is resistant to the leaching of aluminium in the $\mathrm{NaOH}$ solution and exhibits different electrochemical behaviour [8]. The NiAl phase can be created and destroyed during the simulation via the diffusion of $\mathrm{Ni}$ and $\mathrm{Al}$ atoms although this phase is not included as a starting constituent of the simulations. 


\section{Results and discussion}

Modelling the leaching of NiAl alloys to produce Raney-Ni catalysts using the kMC method leads to inherent advantages and disadvantages. kMC allows realistic timescales to be achieved that can be related to experimentation, whereas longer times are hard to achieve using molecular dynamics methods. There is no requirement by kMC for thermodynamic equilibrium; however mechanisms and associated energy barriers have to be known - in this case two have been identified. Using the BKL algorithm, the time increment alters as mechanisms become more or less prevalent, which can be beneficial. A drawback of using kMC for modelling the leaching of large NiAl powders is large CPU times. This requires efficient coding of the model, data structures etc. Finally, it is accepted that the Arrhenius law may not be fully adequate, such as when kinetic energy is accumulated when crossing a barrier and can be used to cross other barriers.

Below are very preliminary results from using the $\mathrm{kMC}$ model, examining the effect of composition and crystal structures of the phases present. In addition, the relative leaching behaviour of the two phases is assessed, including the orientation of the particular phases exposed to the aqueous $\mathrm{NaOH}$ solution.
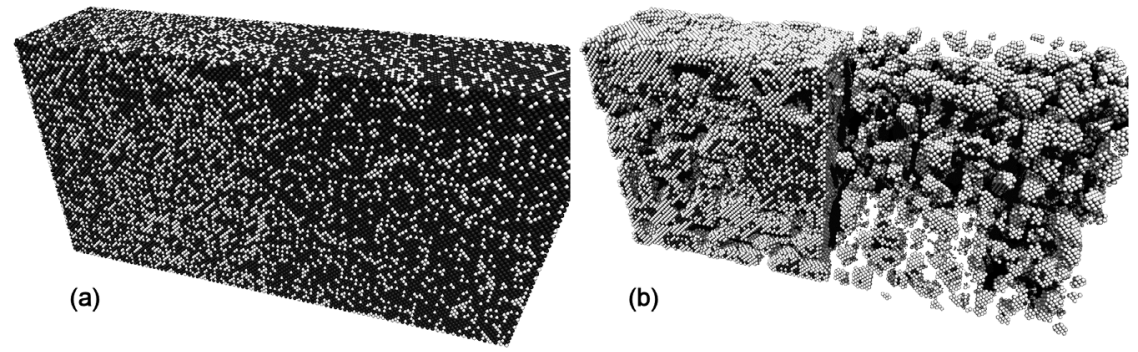

Figure 2: $\quad$ Solid solution of Ni-Al (Ni - light, Al - dark, FCC assumed). Mesh: left-hand side 60at.\%Al, right hand side 75at.\%Al; (a) initial mesh, and (b) after leaching.

\subsection{Effect of composition alone}

Shown in figure 2 is a hypothetical FCC solid solution of Ni and $\mathrm{Al}$ where the right-hand side of the mesh contains 15at.\% more Al than the left. During the simulation, the $75 \mathrm{at} . \% \mathrm{Al}$ is subject to a higher degree of $\mathrm{Al}$ removal. The higher $\mathrm{Al}$ content in contact with the $\mathrm{NaOH}$ solution permits more rapid dissolution, in addition to a larger amount of permitted sites for the Ni adatoms to diffuse to, exposing further $\mathrm{Al}$ atoms.

The faster break-up of the higher Al-composition region in an advancingfront-type reaction and the greater cohesion of the lower Al-composition region can be seen in figure 2. This behaviour tends to agree with observation and lent some initial confidence in the use of the kMC method. 


\subsection{Effect of atomic arrangement}

As stated previously, $\mathrm{NiAl}_{3}$ and $\mathrm{Ni}_{2} \mathrm{Al}_{3}$ phases have a different crystallography to one another. Figure 3 incorporates the crystal structure of the $\mathrm{NiAl}_{3}$ phase, whilst still approximating the $\mathrm{Ni}_{2} \mathrm{Al}_{3}$ as regions of solid solution. It can be seen from figure 3 that the crystal structure of the $\mathrm{NiAl}_{3}$ promotes a structure to be formed that is much changed from the solid solution. The solid solution $\mathrm{Ni}_{2} \mathrm{Al}_{3}$ maintains the same form during leaching, although in this case there has been a build up of nickel at the entrance to adjacent developing nanopores. The effect of this would be that it would further reduce the $\mathrm{Al}$ removal rate of the $\mathrm{Ni}_{2} \mathrm{Al}_{3}$. The formation of these pores would inevitably effect the diffusion and thereby affect processes occurring [9].
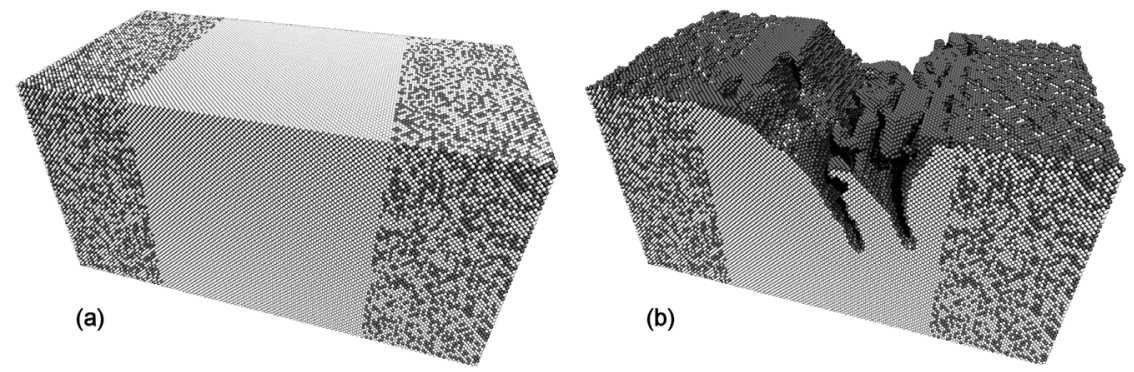

Figure 3: Approximated $\mathrm{NiAl}_{3}$ crystallography in central region, hypothetical random solid solution assumed for $\mathrm{Ni}_{2} \mathrm{Al}_{3}$ at either edge. $\mathrm{Ni}-$ dark and $\mathrm{Al}$ - light; (a) initial mesh, and (b) after leaching.

Finally, using the assumptions outlined in section 2.3.1 and 2.3.2, and applying the same lattice parameter to both phases, it was possible to construct a simple cubic orthogonal computational mesh containing structured regions of both phases of interest. This is shown in figure 4(a).

Simply from observation, the $\mathrm{NiAl}_{3}$ phase (right) in figure 4(a) should break up more quickly than the $\mathrm{Ni}_{2} \mathrm{Al}_{3}$ phase present (left), owing to the fact that there exists a layer of $\mathrm{Al}$ over the $\mathrm{NiAl}_{3}$, whereas the $\mathrm{Ni}_{2} \mathrm{Al}_{3}$ phase is covered with $\mathrm{Ni}$ atoms. Initially, removal of aluminium from the $\mathrm{Ni}_{2} \mathrm{Al}_{3}$ would require diffusion of the $\mathrm{Ni}$ or removal of $\mathrm{Al}$ from the $\mathrm{NiAl}_{3}$ phase at the interface of the two phases.

As expected, the $\mathrm{NiAl}_{3}$ phase disintegrates much more quickly than $\mathrm{Ni}_{2} \mathrm{Al}_{3}$, which can be seen from above in figure 4(b). The leaching from the $\mathrm{NiAl}_{3}$ phase reveals a structure that is comparable to that which characterises a Raney-Ni catalyst. Importantly, figure 4(b) also shows that FCC Ni forming over both phases.

\subsection{Orientation of exposure}

Until this point, leaching has only been simulated as occurring in [100]-type directions (i.e. from the top of the orthogonal mesh in figure 4 downwards). In an attempt to consider more orientations, a spherical particle is modelled to take 
account of multi-directional exposure to the $\mathrm{NaOH}$ solution. The starting spheres of the $\mathrm{NiAl}_{3}$ and $\mathrm{Ni}_{2} \mathrm{Al}_{3}$ are shown in figure 5(a). The spherical regions of each phase shown in figure 5 represent particles that have radii of approximately 100 atoms. It is recognised that this is much smaller than the real particles, highlighting the need for improvements to both memory efficiency and code optimisation in order to model larger particles.

(a)

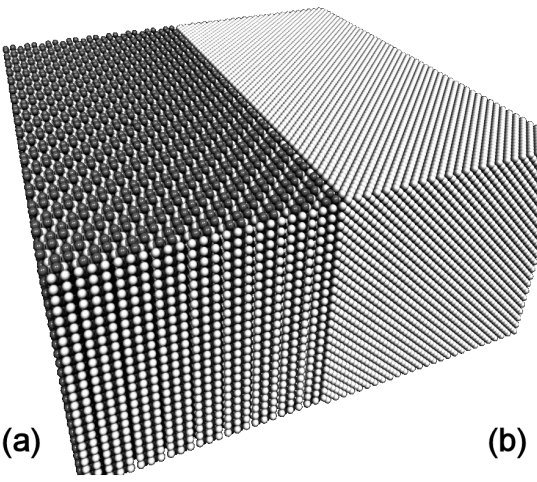

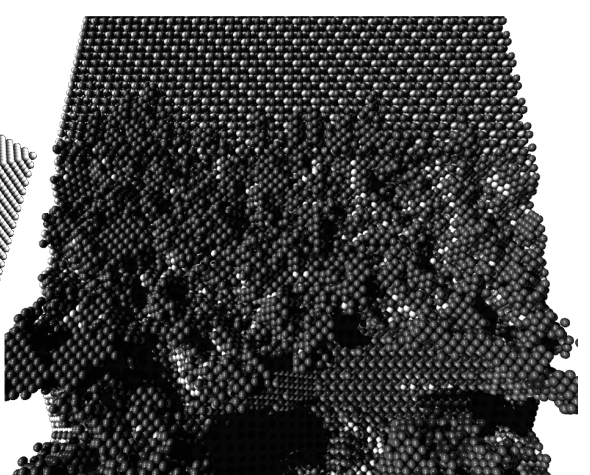

Figure 4: $\quad \mathrm{NiAl}_{3}$ and $\mathrm{Ni}_{2} \mathrm{Al}_{3}$ (left and top in (a) and (b) respectively) structures included. (a) initial mesh, and (b) after leaching: $\mathrm{Ni}$ - dark and $\mathrm{Al}$ light.

The spheres represented in figure 5(a) have been leached from all exposed surfaces to produce the structures shown in figure 5(b). The resulting leached simulated structures that can be seen in figure 5(b) once again show a greater break-up for the $\mathrm{NiAl}_{3}$ phase and a greater cohesion demonstrated by the $\mathrm{Ni}_{2} \mathrm{Al}_{3}$ phase. However, this difference is far less pronounced in this case than for the [100]-type dissolution in figure 4, indicating that the starting condition/position is critical at the start of a simulation. The surface of the leached spheres for both cases is predominantly $\mathrm{Ni}$, although on-going experimentation suggests that a higher $\mathrm{Al}$ content would be expected.

Figure 5(b) shows that the $\mathrm{Ni}_{2} \mathrm{Al}_{3}$ particle contains a greater number of $\mathrm{Al}$ atoms within the evolving pores. This may be recently revealed $\mathrm{Al}$ atoms that have not been removed, but may also be the NiAl phase described in section 2.3.3, which would be identified in the simulation and prevent Al being removed from this phase in contact with the $\mathrm{NaOH}$ solution. In addition, the structural changes that take place in $\mathrm{Ni}_{2} \mathrm{Al}_{3}$ phase during caustic leaching is a topic of much debate [10]. Predictions made by a model with respect to these structural changes would be of much interest.

Figure 6 shows the removal rate $(\mathrm{R})$ of $\mathrm{Al}$ and the total number of atoms exposed at the surface $(\mathrm{N})$ for both cases in figure 5. For the $\mathrm{Ni}_{2} \mathrm{Al}_{3}$ particle, despite being haphazard, a fairly constant removal of $\mathrm{Al}$ was observed with a continually increasing surface area, shown in figure 6(a) (left). In contrast, the $\mathrm{NiAl}_{3}$ particle in figure 5 showed a rapid rate of $\mathrm{Al}$ removal, which is completed earlier on reflecting the quicker break-up of this phase, figure 6(b) (left). The 
number of atoms at the surface of the $\mathrm{NiAl}_{3}$ particle increases much more quickly than $\mathrm{Ni}_{2} \mathrm{Al}_{3}$, a constant level is reached after a relatively short time, figure 6(b) (right). It also appears that the $\mathrm{NiAl}_{3}$ particle is beginning to coarsen (i.e. a slightly decreasing surface area) after further time by surface diffusion of $\mathrm{Ni}$ and coarsening leading to a reduction in the number of atoms present at the surface, shown in figure 6 (right).
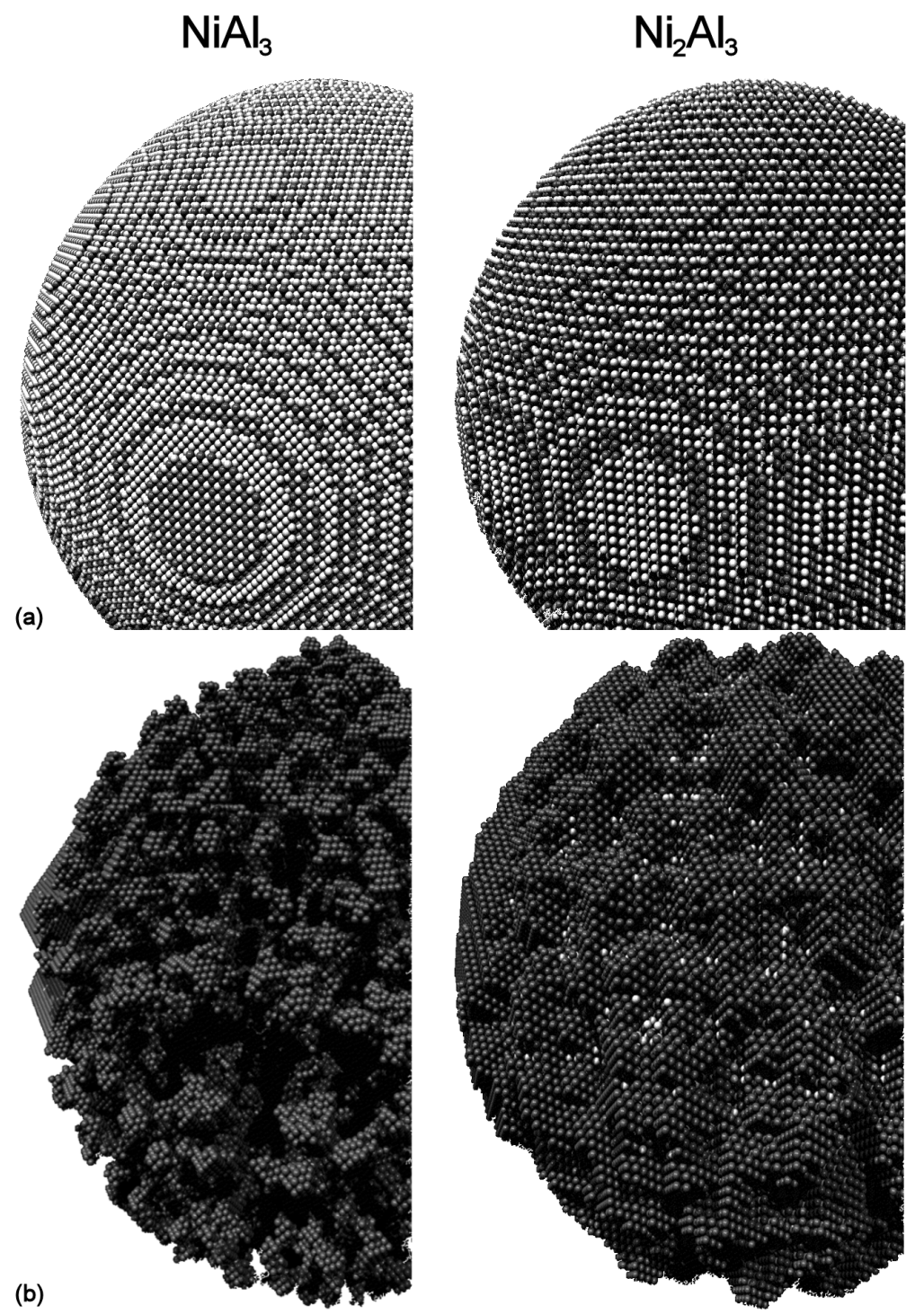

Figure 5: Simulated single-phase spheres of $\mathrm{NiAl}_{3}$ and $\mathrm{Ni}_{2} \mathrm{Al}_{3}$ phase structure; (a) $t=0$, and (b) $t=200 \mathrm{~s}$. (N.B. these are not representative of a multi-phase powder.) 
(a)
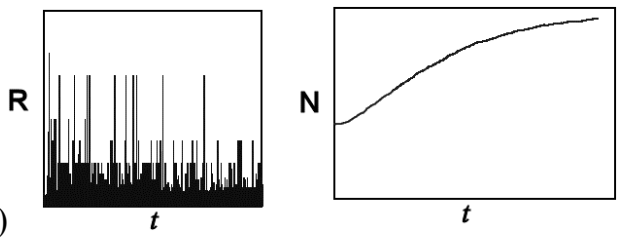

(b)
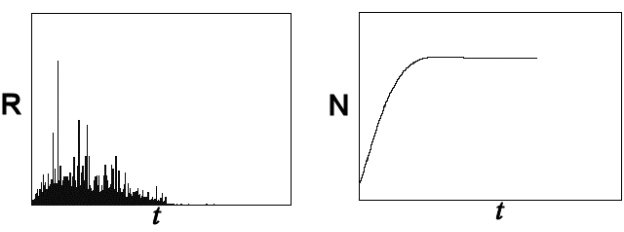

Figure 6: The rate of aluminium removal (atoms/s), R, and the number of atoms at the surfaces of the octants shown in figure 5 over time, $t$; (a) $\mathrm{Ni}_{2} \mathrm{Al}_{3}$, and (b) $\mathrm{NiAl}_{3}$.

\section{Conclusions}

The prototype kMC model appears capable of simulating features of the leaching process assuming that all the relevant physiochemical processes taking place have been included and assigned appropriate rates. It has been shown that the leaching of hypothetical solid solutions appears logical. The $\mathrm{NiAl}_{3}$ and $\mathrm{Ni}_{2} \mathrm{Al}_{3}$ phases that are present in cast-and-crush and spray-atomised NiAl powders can be approximately represented on a simple cubic computational grid using some simple assumptions and minor adjustments in lattice parameters. The simulated leaching of these phases can be seen to progress as would be expected and yield leached structures close to those observed for NiAl alloys leached with aqueous $\mathrm{NaOH}$. Future work will concentrate on improving the quantitative nature of the model, attempting to link the predicted morphologies to catalytic behaviour and increasing the size of the computational domain to be able to deal with realistically sized particles.

\section{Acknowledgements}

The authors would like to acknowledge financial support from the EU from the IMPRESS Integrated Project (contract no. NM3-CT-2004-500635) and also several useful discussions with F. Devred and J.W. Bakker at Leiden University in Holland.

\section{References}

[1] Devred, F., Hoffer, B.W., Sloof, W.G., Kooymana, P.J., van Langeveld, A.D. \& Zandbergen, H.W., "The genesis of the active phase in Raney- 
type catalysts: the role of leaching parameters." Applied Catalysts A, 2003. 244: pp. 291-300.

[2] Tanaka, S., Hirose, N., Tanaki, T. \& Ogata, Y.H., "Effect of Ni-Al precursor alloy on the cathodic activity for a Raney-Ni Cathode." Journal of the Electrochemical Society, 2000. 147(6): pp. 2242-2245.

[3] Lee, G.D., Suh, C.S., Park, J.H., Park, S.S., \& Hong, S.S., "Raney Ni catalysts derived from different alloy precursors (I) morphology and characterization." Korean Journal of Chemical Engineering, 2005. 22(3): pp. 375-381.

[4] Lee, G.D., Moon, M.J., Park, J.H., Park, S.S., \& Hong, S.S., "Raney Ni catalysts derived from different alloy precursors (II) $\mathrm{CO}$ and $\mathrm{CO}_{2}$ methanation activity." Korean Journal of Chemical Engineering, 2005. 22(4): pp. 541-546.

[5] Tanaka, S., Hirose, N., \& Tanaki, T., "Evaluation of Raney-Nickel Cathodes Prepared with Aluminium Powder and Titanium Hydride Powder." Journal of The Electrochemical Society, 1999. 146(7): pp. 24772480.

[6] Erlebacher, J., Aziz, M.J., Karma, A., Nikolay, D. \& Sieradski K., "Evolution of nanoporosity in dealloying." Nature, 2001. 410: pp. 450453.

[7] Zacate, M.O., \& Collins, G.S., "Site preferences of hyperfine impurities in $\mathrm{Ni}_{2} \mathrm{Al}_{3}$ phases." Hyperfine Interactions, 2002. 136/137: pp. 647-652.

[8] Lillard, R.S., \& Scully, J.R., "Electrochemical passivation of ordered NiAl." Journal of the Electrochemical Society, 1998. 145(6): pp. 20242032.

[9] Saravanan, C., \& Scott, S.M., "Theory and simulation of cohesive diffusion in nanopores: Transport in subcritical and supercritical regimes." Journal of Chemical Physics, 1999. 110(22): pp. 11000-11011.

[10] Wang, R., Lu, Z., \& Ko, T., "The structural transitions during leaching of $\mathrm{Ni}_{2} \mathrm{Al}_{3}$ phase in a Raney Ni-Al alloy." Journal of Materials Science, 2001. 36: pp. 5649-5657. 